\title{
Laser Assisted Dye-sensitized Solar Cell Sealing: from small to large cells areas
}

\author{
Fernando Ribeiro ${ }^{1}$, José Maçaira ${ }^{2}$, Isabel Mesquita ${ }^{2}$ Joaquim Gabriel $^{1}$, Luísa Andrade ${ }^{2}$, Adélio \\ Mendes $^{2}$ \\ ${ }^{1}$ IDMEC - Pólo FEUP, Faculdade de Engenharia, Universidade do Porto, Rua Dr. Roberto Frias, s/n 4200-465 \\ Porto, Portugal \\ ${ }^{2}$ LEPAE, Departamento de Engenharia Química, Faculdade de Engenharia, Universidade do Porto -, Rua Dr. \\ Roberto Frias, s/n 4200-465 Porto, Portugal \\ mendes@fe.up.pt
}

\section{Abstract}

The long-term stability problem of dye sensitized solar cells (DSCs) modules is essentially related to their sealing. Thermoplastic sealants are normally used to bond the two glass substrates of a DSC. However, these thermoplastic sealants, such as $\operatorname{Surlyn}^{\circledR}$, are permeable towards ambient water vapor, UV sensitive and they cannot be used above $60{ }^{\circ} \mathrm{C}$ [1]. Sealing is therefore the Achilles' heel of DSCs, which is presently preventing their commercialization.

Laser assisted glass-frit sealing can be a very interesting alternative sealing technique, as it has been demonstrated on microelectromechanical systems (MEMS) assembly. However, for these applications the laser is shot around the sealing perimeter several times in a loop pattern. Nevertheless, for sealing large areas without heating the samples this method cannot be applied since the laser loop takes more than 1second, which is too long for an effective low-temperature glass-frit sealing.

In the present work is described a laser assisted sealing technique that is independent of the sealing border path format applied to several cells' and modules' shapes and sizes. This technique is suitable for DSCs manufacture and can be implemented in an inline production plant. For the same cell format, efficiencies of the glass-sealed and conventional sealing were compared. Stability studies were also presented to evidence the effectiveness of the hermetic sealing obtained with the sealing assisted technique applied to DSCs. 


\section{Introduction}

Solar resource in Europe and worldwide is abundant and is the only offering the perspective of a cost reduction in the future. In particular, the European southern countries have a privileged geographic location in terms of solar exposition, giving them the opportunity of becoming world leaders in photovoltaics exploitation [2]. The EU strategy 20-20-20 reveals this commitment, targeting a $20 \%$ reduction of $\mathrm{CO}_{2}$ emissions, $20 \%$ of increase in energy efficiency and $20 \%$ of energy share coming from renewable sources by the year of 2020 [3]. Under these orientations a new concept of buildings arises - the Net Zero-Energy Buildings - in which the building should have zero net energy consumption and zero carbon emissions over the course of one year. In the next decades the buildings must be strictly designed in compliance with this requirement. Two main actions can be implemented to achieve this goal under these new policies:

i. an increase on the building energy efficiency;

ii. generation of energy from renewable energy sources perfectly integrated in the building, aiming energy production in the point of consumption.

In the last decade, solar and photovoltaic (PV) technologies have emerged as a potentially major technology for power generation. However, so far, the PV field has been dominated by devices in which the junction consists of inorganic solid-state materials, usually silicon, profiting from the expertise of the semiconductor industry. Nevertheless, the diversification of technologies in this field is of extremely importance in order to contribute to a strong PV sector, able to fulfill different needs with competitive costs [4]. Technologies like organic solar cells or quantum dot solar cells are examples of this group, claimed as "Emerging PV technologies". For the energy production in urban environments, solar energy is one of the available sources with more potential that can be directly converted to electricity using photovoltaic modules and with great potential for architectural integration [5]. Thus, buildingintegrated photovoltaics (BIPV) will be in the future the solution for a less dependency of the nuclear/carbon powered production plants. 
Dye-sensitized solar cells (DSC), also known as Grätzel solar cells, are an important type of thin-film photovoltaics due to their potential for low-cost fabrication and versatile applications, as flexible or light-weight products and for building integration purposes. State of the art lab DSCs achieve now $14.9 \%$ energy conversion on small area devices [6-8]. Recent findings indicate that DSC modules could reach the cost targets below $1 € / \mathrm{Wp}$ in a near future [9]. DSCs consist of a porous nanocrystalline $\mathrm{TiO}_{2}$ layer deposited onto a transparent conducting oxide (TCO) glass substrate and coated with a monolayer of dye. Light harvesting is accomplished by this monolayer of dye chemically bonded to the surface of $\mathrm{TiO}_{2}$ particles. Under illumination, the dye absorbs the radiation and, once excited, electrons are injected into the conduction band of $\mathrm{TiO}_{2}$. The photoinjected electrons then percolate through the semiconductor network, being collected at the TCO. Following electron injection, oxidized dye molecules are regenerated by electron donation from the electrolyte solution containing a redox couple of iodide/triiodide. The triiodide ions formed in the semiconductor's surface during the redox reaction diffuse to the Pt-catalyzed counter-electrode (CE), where they are reduced back to iodide by the electrons from the external circuit $[10,11]$.

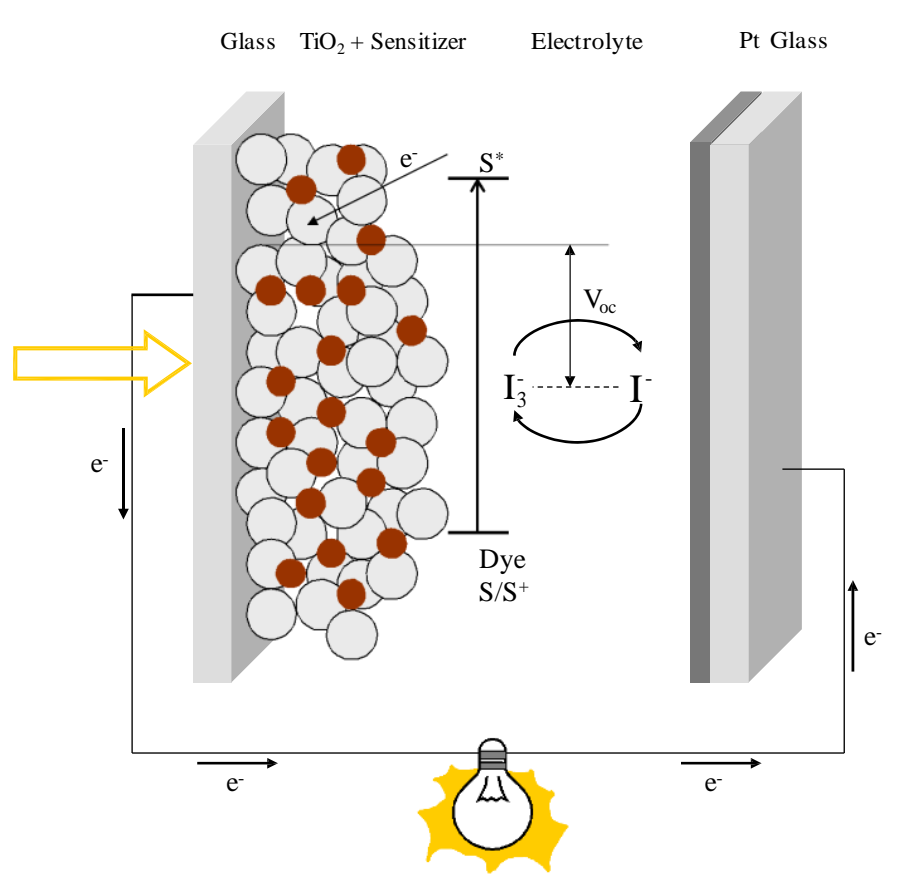

Figure 1 - Scheme of a dye-sensitized solar cell. 
Dye-sensitized solar cells have shown to be a good solution for BIPV. DSC's cell efficiencies are being improved in the last years, what placed them on the head of this emerging group. The small dependency of direct radiation and the glass substrate structure assembly make them suitable for external windows and facades applications. However, the long-term applications are not yet possible. The current sealing method uses a thermoplastic sealant that suffers from UV degradation and thermal cycling ageing. On the other hand, glass-frit materials were also used for sealing DSCs devices, though glass-frits with low softening points cannot be used as a DSC sealing material since they have lead in their composition and they can react with the DSC electrolyte. Moreover, their high processing temperatures of ca. $600{ }^{\circ} \mathrm{C}$ is also incompatible with the stability of the inner-components of the DSCs [12]. Even though, lead-free glass-frit sealing has potentially several benefits: it is possible to assembly a leak free device; it allows to obtain a hermetic device able to sustain severe aging tests; it is not degraded by the sun radiation and the glass-frit composition can be formulated to have a thermal expansion similar to the glass substrate [12]. Thus, the use of a laser assisted glass sealing process, instead of using the traditional pressure/thermal processes, was identified as a potential route for overcoming this limitation. Actually, laser joining techniques have been developed to encapsulate miniature MEMS [13]. These techniques allow dissimilar materials to be joining together. However, they require surface treatments for turning the surfaces rough enough if a bonding material is used, [13] or for making the surfaces smooth and clean if no bonding material is used [14]. Moreover, those techniques are usually dependent on the glass-frit cord shape and they are not suitable for scaling up to large areas, as needed for BIPV applications.

This work presents a laser assisted glass-frit bonding technique applied to dye-sensitized solar cells sealing. The recently developed technique allows the manufacture of several cell/modules formats, since it is independent of the shape and design of the devices. Firing a laser beam directly into a glass- frit cord, with specific optical characteristics, produces the necessary heat energy to melt the frit and to form a hermetic sealing ring between the two substrates. To prevent thermal tensions induced by the laser beam in the glass material, the glass substrates are pre-heated to an intermediated temperature, well below the temperature needed for sintering the counter- and photo-electrodes. This 
new process does not require application of high pressure on the substrates, even any surface treatment of the glass and glass-frit cords. The heat generated by the laser beam on the glass-frit cord is localized and the other DSC components are not affected [15]. This is actually a great breakthrough on this technology and strongly contributes to foster the entrance of DSCs technology on the very competitive PV market.

\section{Methods}

The new sealing technique was applied on soda-lime glasses coated with fluorine doped tin oxide $\left(\mathrm{FTO} / \mathrm{SnO}_{2}: \mathrm{F}\right)$ conducting films supplied by Solaronix. The glass-frit cords were printed on the glass substrates using a screen-printer and the glass paste burned out to remove the organic components. The glass paste is supplied by AGC-ASAHI Glass Company, Ltd. The optical characteristics of the coated glass and glass-frit were measured using a LambdaTM $750 \mathrm{UV} / \mathrm{Vis} / \mathrm{NIR}$ spectrophotometer from PerkinElmer - Figure 4.

Laser scribing (Universal VersaLaser 2.30) is used to interrupt the transparent conductive layer between the cells. Titanium dioxide and platinum catalyst were screen-printed after the glass paste burn out step. These components were also sintered using the suppliers' procedures. Commercial materials were used as photo-electrode and catalytic counter electrode material to validate the newdeveloped sealing technique.

The sealing step was performed in a home-made laser box that has a two dimensional (2D) mirror scan system for directing the laser beam through f-theta-ronnar lens. An infrared ytterbium fiberdelivered diode laser is used. The laser system is setup to apply a focus laser beam with $64.5 \mu \mathrm{m}$ of diameter. The applied laser power determines the space between the two glass substrates; to ensure a distance range of $30-50 \mu \mathrm{m}$, laser powers of 30 to $45 \mathrm{~W}$ were used. An aluminum heating plate was used for pre-heating the glass substrates to temperatures above the glass frit softening point, usually less than $330{ }^{\circ} \mathrm{C}$ [16]. The tuning of the laser scan pattern (velocity and power) was reported elsewhere [15]. The ruthenium based dyes used in DSCs do not stand temperatures above $80{ }^{\circ} \mathrm{C}$ for a 
long time, but the temperature achieved during the sealing process is much higher. This way, the dye was introduced in the DSC after sealing by recirculating during 6 - 12 hours - Figure 2 [17]. A solution of commercial ruthenium-based dye $(0.5 \mathrm{mM}$ concentration in ethanol) was used. After the dying process, the cells were filled up with a commercial triiodide-iodide based-electrolyte. The holes on the laboratorial cells were sealed using Surlyn ${ }^{\circledR}$ discs. For mass production a glass-frit hole sealing is under development.

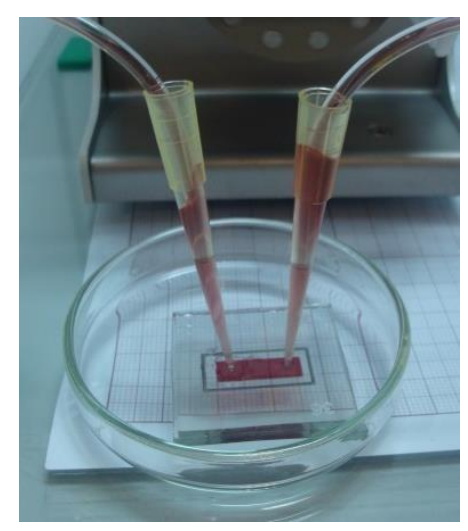

Figure 2 - Dye recirculation process.

A more detailed diagram of the counter- and photo- electrode preparation is shown in Figure 3. 


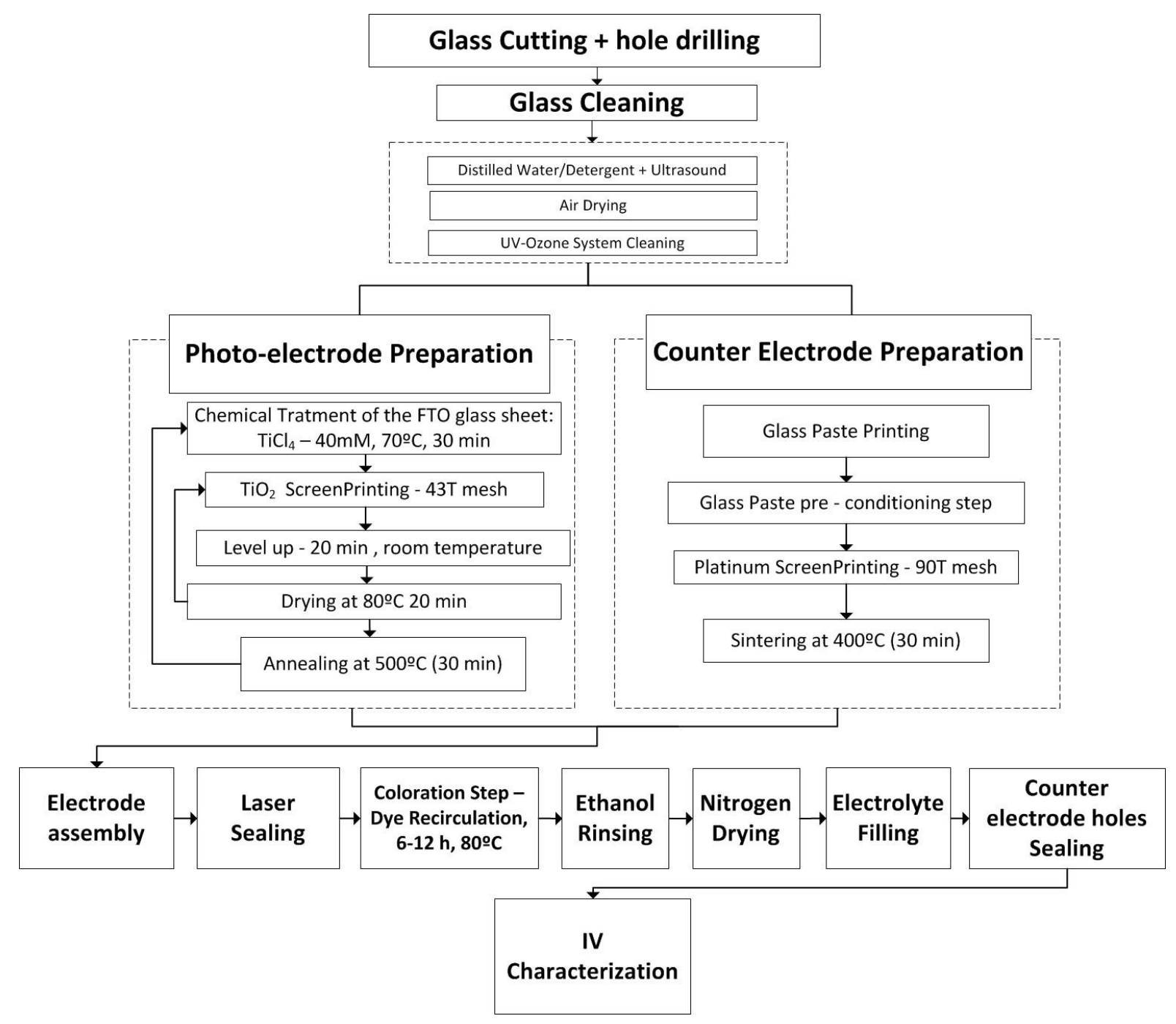

Figure 3 - DSC production method.

\section{Results}

The optical characteristics of the glass paste and the bare TCO glass were obtained by absorbance spectroscopy. The glass paste shows high absorbance in the near infra-red part of the spectrum Figure 4. The absorbance pick is not in the Nd:YAG laser wavelength; although, the measured absorbance is still high when compared to the bare glass substrate absorbance. This explains why only the glass-frit is heated by the laser; the heating of the glass substrate occurs mainly by conduction and radiation. 


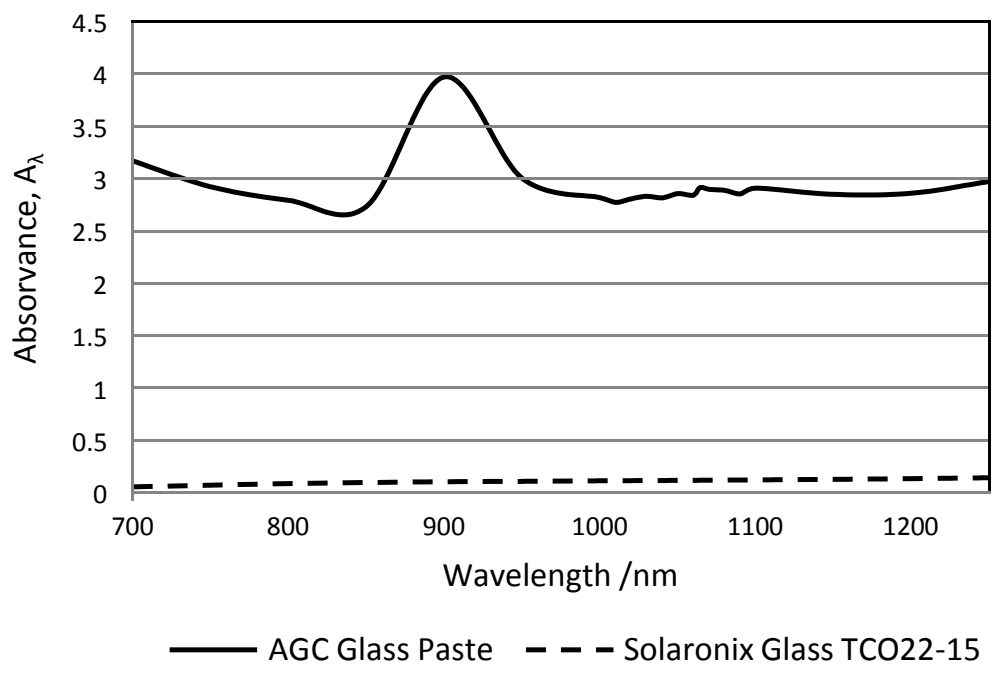

Figure 4 - Absorbance spectrum measured for AGC glass paste and Solaronix coated glass.

With the described laser assisted technique is possible to build from small cells $\left(0.2 \mathrm{~cm}^{2}\right.$ of active area) to large cells $\left(200 \mathrm{~cm}^{2}\right)$ with different formats: squared, rectangular or circular. The printed glass-frit cords and the used laser power ensure a uniform distance between the substrates $(30-50 \mu \mathrm{m})$, suitable for DSCs application. Hermeticity of the laser assisted glass-frit sealing was been tested, showing good results when compared with the traditional Surlyn ${ }^{\circledR}$ sealing $[15,18]$.

Figure 5 is a circular cell for high efficiency lab cells. The two holes for dye recirculation and electrolyte injection can be drilled in the counter-electrode side. 


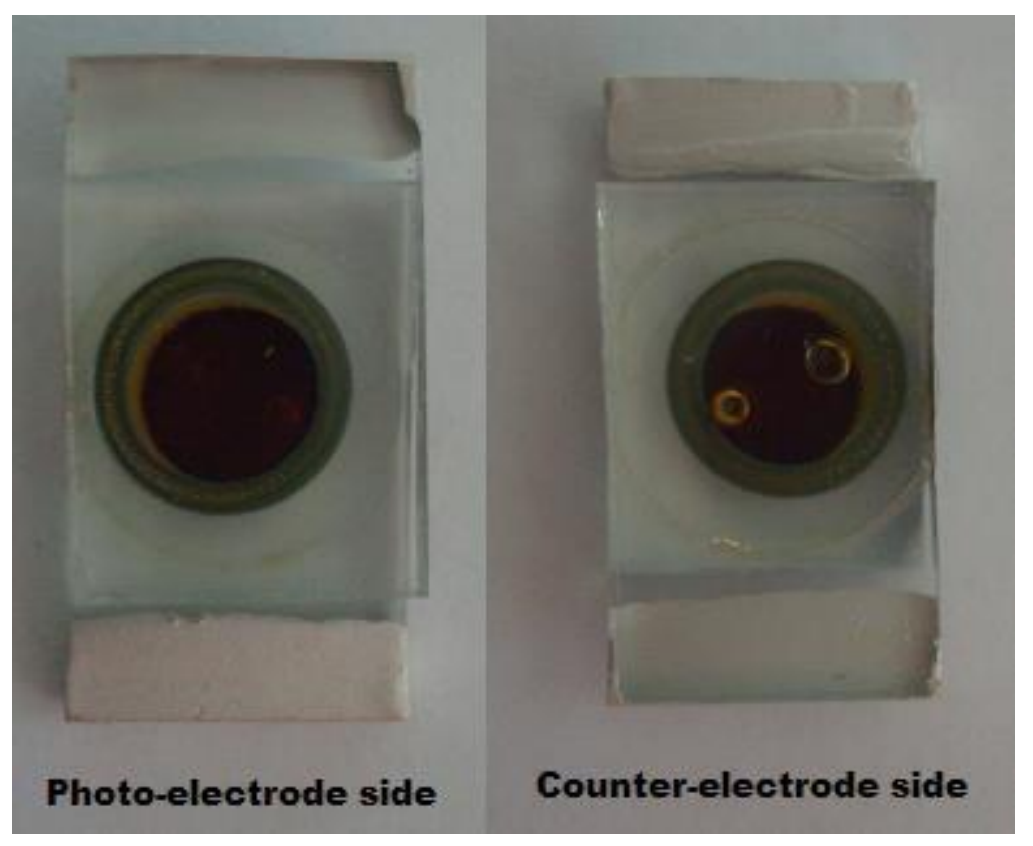

Figure 5 - Laboratorial cell format, with the two recirculation holes placed on the counter-electrode side.

Different formats of cells and modules were sealed, always using the same process parameters. An individual DSC deliveries approximately $0.6 \mathrm{~V}$ independently of the active surface. However, the standard invertors need $24 \mathrm{~V}$ and thus the cells should be associated in series for producing this voltage. Actually, an integrated series of cells is generally favored to several cells plugged in series due to simplified processing methods, cost-efficiency and aesthetic appearance. For series interconnected module design, all cells are manufactured simultaneously arranged either as Z- or W- configurations $[19,20]$. Each of these arrangements shows advantages and disadvantages. In Z- type high efficiencies are obtained since a scattering layer can be applied on top of the nanostructured semiconductor and there are no imbalances between the single cells because the photo and the counter-electrodes are placed on different substrates. In what concerns $\mathrm{W}$-arrangement, the main advantage is that no silver lines are required to lift the electric current from one electrode to the other and so it has a simpler fabrication process. However, this in series-connection is only cost-effective if its performance is improved since no scattering layer can be used because the photo and the counter- electrodes are placed on the same substrate in turn [21]. 
In the series connection W-type, the photo and the counter-electrodes are placed on the same substrate in turn, delivering identical output when illuminated from either side. The TCO layer on the glass substrate is structured by laser scribing. After the sintering process of both electrodes, the two substrates are aligned on top of each other, placing one CE substrate on top of the PE of the other substrate. A hermetic seal between the cells is obtained and the electrical W-contact is formed.

To construct the W-type panel modules, two assembly methods were used. In the first there is no space between two consecutive cells. The required laser scribing on the TCO layer is embedded on the glass-frit cord - Figure 6. The same glass-frit cord is used to separate the cells - Shared glass-frit cord sealing. The second method is to individualize the cells with the creation of a free space between them Figure 7 - Double glass-frit cord sealing method. That space can be occupied only by the laser scribing or also for vertical electric connection. This last case also allows prepare Z-type panel modules. For this integrated series connection, the TCO layer coated on the glass substrate is structured by laser scribing. Then, the semiconductor and the counter-electrode layers are screen printed on the respective substrates at the same time than the lifting silver lines and the sealant material (either Surlyn ${ }^{\circledR}$ or glass cords). The sealant material is screen-printed as a protective barrier of the silver lines on both sides [22]. After the sintering process of both PE and CE, the latter is aligned on top of the PE and sealed according to the sealant material characteristics [12]. A hermetic seal around the silver lines is obtained and the electrical Z-contact is formed - Figure $\mathbf{8}$.

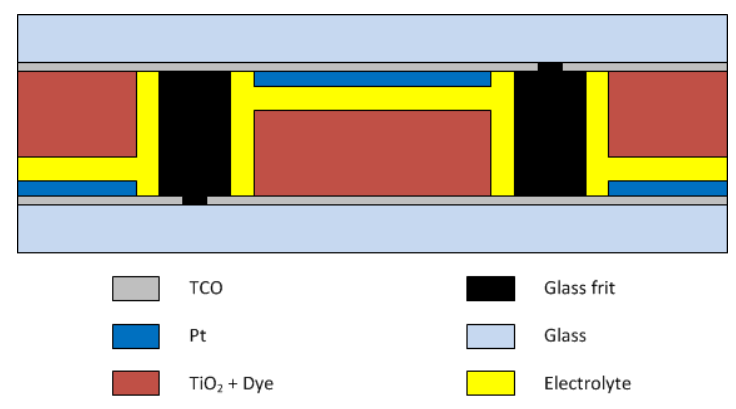

Figure 6 - Shared glass-frit cord sealing method (W-configuration). 


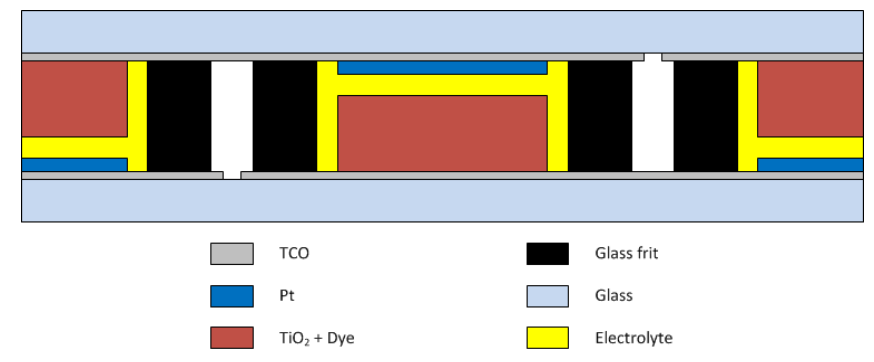

Figure 7 - Double glass-frit cord sealing method (W-configuration).

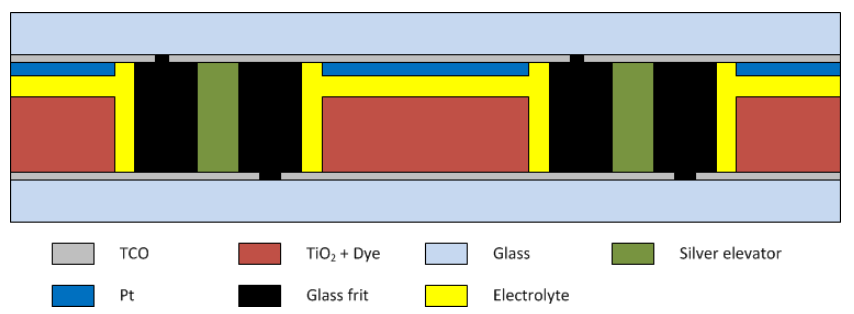

Figure 8 - Double glass-frit cord sealing method with the TCO cut embedded on the sealing (Zconfiguration).

Figure 9 shows a W-type four cell module. The module is formed by 4 individualized cells. The scribing is made before sealing in the space between the cells. Notice that as in this module the number of cells is pair, the external contacts are localized in the same substrate.

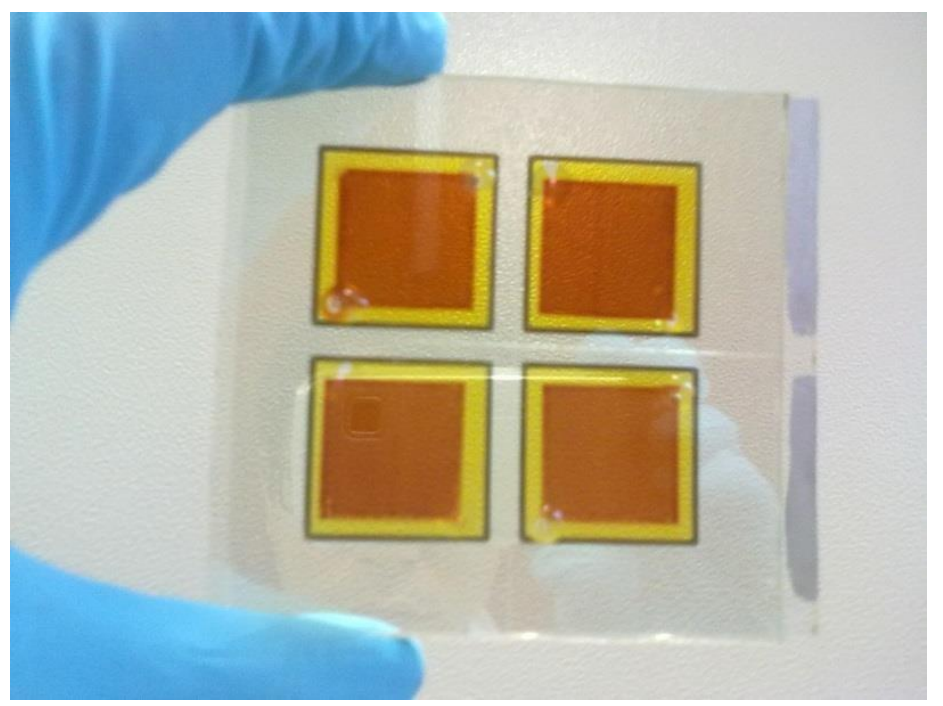

Figure 9 - W-type four cell module, with double glass-frit cord sealing method. 
Functional modules were already assembled for demonstrate the versatility of these devices. In it can be seen a $100 \times 100 \mathrm{~mm}^{2}$ module. The module was assembled using the shared glass-frit cord method. This configuration showed to be very efficient as the series resistance of the TCO layer is highly minimized. This is a very complex format, with glass-frit cord intersections and a length of cord approximately of $1200 \mathrm{~mm}$. As the module has an odd number of cells, the electrical contact is placed in each substrate. Notice that with this sealing technique the cords are not heated at the same time as the usual glass-frit sealing. Instead, the laser seals each cell consecutively and in some points the laser could pass it over more than once.

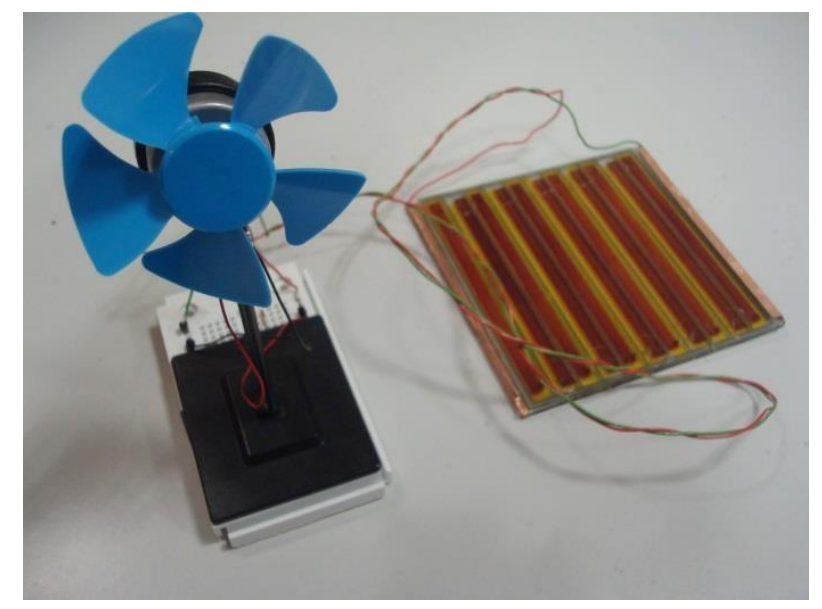

Figure 10 - Functional DSC module supplying energy for a DC motor.

Figure 11 shows a $300 \times 300 \mathrm{~mm}^{2}$ module, proving that the sealing technique can be applied for large cell and modules format. This was specially designed to show the possibility of integrating DSCs on windows.

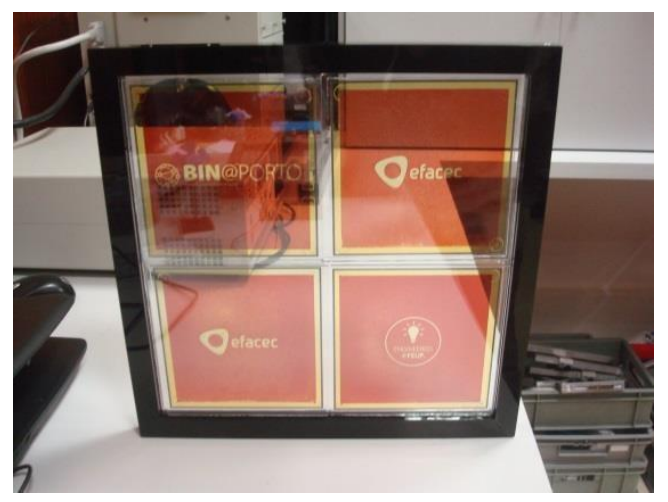

Figure 11 - Laser assisted glass-fit sealed 300 x $300 \mathrm{~mm}^{2}$ DSC module. 
In order to check whether the laser assisted sealing method affects or not the performance of the DSC, two sets of devices were prepared and compared. Both devices were prepared with the same commercial available materials. On the other hand, the sealing technique employed and the dye adsorption method were different: the dye was recirculated for the laser assisted sealed cell and for the Surlyn ${ }^{\circledR}$-sealed devices, the dye was adsorbed into the titanium dioxide by dipping the photo electrodes into the dye solution. Figure 12 shows the $I-V$ curves and the characteristic performance values for each set of devices. The fill factor parameter of both devices indicates that the DSCs were well prepared and that there are no differences between both preparation methods. The only difference is verified for the short circuit current; the laser sealed devices showed higher currents, fact that may be attributed to the dye adsorption method.

\begin{tabular}{ccc} 
Characteristics & & \\
\cline { 1 - 2 } Type of sealing & $\begin{array}{c}\text { Surlyn }^{\circledast} \\
\text { (dipping) }\end{array}$ & $\begin{array}{c}\text { Laser } \\
\text { (recirculation) }\end{array}$ \\
$I_{s} / \mathrm{mW} \mathrm{cm}{ }^{-2}$ & 100 & 100 \\
$V_{o c} / \mathrm{V}$ & 0.72 & 0.74 \\
$J_{s c} / \mathrm{mA} \mathrm{cm}{ }^{2}$ & 9.32 & 10.75 \\
& & \\
$\mathrm{FF}$ & 0.76 & 0.75 \\
$\eta / \%$ & 5.13 & 5.99 \\
\hline
\end{tabular}

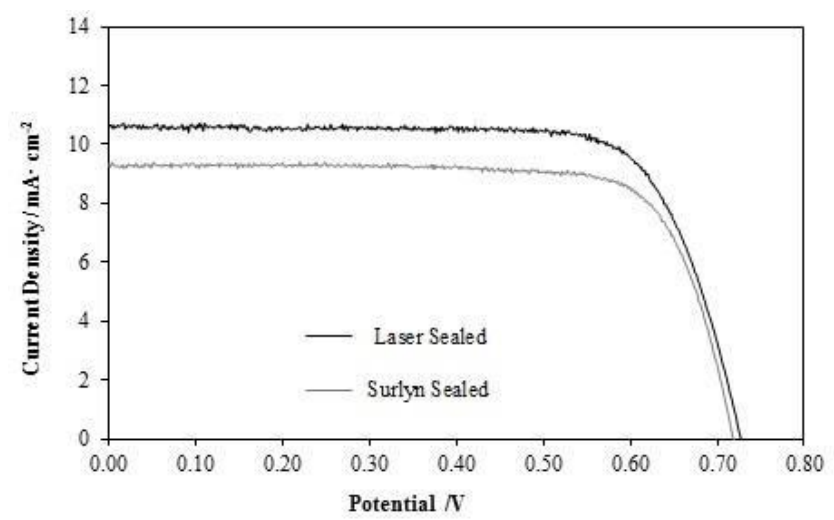

Figure 12 - I-V curves of a glass sealed cell and a cell sealed with thermoplastic polymer Surlyn ${ }^{\circledR}$. (Is

- Insiding light intensity; Voc - open circuit potential; Jsc - short-circuit photocurrent; FF - fill factor; $\eta$ - efficiency)

Empty devices were made. These devices were made bonding the two substrates with a laser assisted glass-frit cord - Figure 13. No cell inner components were printed and the glass substrates had no holes drilled. The samples were submitted a 1000 hours thermal aging test according to the standard IEC 61215 . Samples of $100 \times 100 \mathrm{~mm} 2$ and $5 \times 15 \mathrm{~mm} 2$ were tested. This test was made to verify the samples reaction to cycling substrates thermal expansion/contraction, and the formation of ice outside and inside the sample. The samples demonstrate no morphologic or chemical changes after the test. The substrates remain bonded and the tested liquids (commercial triiodide-iodide based-electrolyte, 
ethanol) didn't enter inside the samples by capillarity, showing that the samples remain sealed after the test.

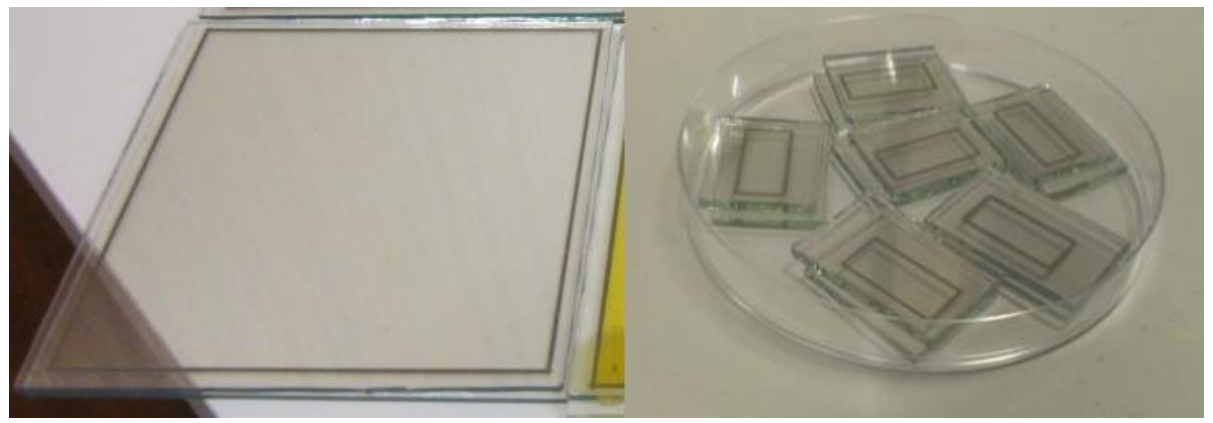

Figure 13 - Empty devices tested according to the standard 61215.

\section{Conclusions}

The present work demonstrates that the laser assisted DSC sealing method does not affect the solar cell efficiency. The performance efficiency difference between glass-frit sealed and Surlyn ${ }^{\circledR}$ sealed cells can only be explained by the absorption method. The same sealing method can be applied to small and large devices with different shapes, thus proving that it can be a capable alternative to the current thermoplastic sealing. The assembly process can be done in line with no special requirements of pressure or vacuum. The sealing can be successfully performed in $\mathrm{W}$ - and Z-type module configurations. Large sealed areas were obtained, showing that the new sealing technology is ready for large areas BIPV applications.

\section{Acknowledgements}

This work was supported by research project WinDSC SI\&IDT (ref. 21539/2011), co-financed by the European Union and the Portuguese Government through AdI - Agência de Inovação, in the framework of the QREN Initiative and the European Regional Development Fund through the Operational Program for Competitiveness Factors and Portuguese Foundation of Science and Technology (Project SolarConcept PTDC/EQU-EQU120064/2010). The authors would like to acknowledge Efacec - 
Engenharia e Sistemas S.A. for the facilities and financial support. Fernando Ribeiro and José Nogueira are grateful to the Portuguese Foundation for Science and Technology (FCT) for their PhD grants with references SFRH/BDE/51737/2011 and SFRH/BD/80449/2011, respectively. Luísa Andrade acknowledges European Research Council for funding within project BIDSC-Building Integrated Dye sensitized Solar Cells (Contract No. 321315).

\section{REFERENCES}

[1] P. Surawatanawong, A.K. Wojcik, S. Kiatisevi, J Photoch Photobio A, 253 (2013) 62-71.

[2] M. Suri, T.A. Huld, E.D. Dunlop, H.A. Ossenbrink, Sol Energy, 81 (2007) 1295-1305.

[3] E. Commission, Europe 2020: a strategy for smart, sustainable and inclusive growth: communication from the Commission, Publications Office, 2010.

[4] P. Frankl, S. Nowak, Technology Roadmap: Solar Photovoltaic Energy, OECD/IEA, 2010.

[5] M. Pagliaro, R. Ciriminna, G. Palmisano, Prog Photovoltaics, 18 (2010) 61-72.

[6] A. Yella, H.-W. Lee, H.N. Tsao, C. Yi, A.K. Chandiran, M.K. Nazeeruddin, E.W.-G. Diau, C.-Y. Yeh, S.M. Zakeeruddin, M. Grätzel, Science, 334 (2011) 629-634.

[7] N.C.f. Photovoltaics, in, National Renewable Energy Laboratory, 2013.

[8] M. Grätzel, S.I. Seok, (2013).

[9] J.M. Kroon, N.J. Bakker, H.J.P. Smit, P. Liska, K.R. Thampi, P. Wang, S.M. Zakeeruddin, M. Grätzel, A. Hinsch, S. Hore, U. Würfe, R. Sastrawan, J.R. Durrant, E. Palomares, H. Pettersson, T. Gruszecki, J. Walter, K. Skupien, G.E. Tulloch, Progress in Photovoltaics: Research and Applications, 15 (2007) 118.

[10] L.M.M. Andrade, Study and characterization of Grätzel solar cells, [s. n.], Porto, 2010.

[11] J. Maçaira, L. Andrade, A. Mendes, Renewable and Sustainable Energy Reviews, 27 (2013) 334349.

[12] R. Sastrawan, J. Beier, U. Belledin, S. Hemming, A. Hinschl, R. Kern, C. Vetter, F.M. Petrat, A. Prodi-Schwab, P. Lechner, W. Hoffmann, Prog Photovoltaics, 14 (2006) 697-709.

[13] Q. Wu, N. Lorenz, K.M. Cannon, D.P. Hand, leee T Compon Pack T, 33 (2010) 470-477.

[14] W. Watanabe, S. Onda, T. Tamaki, K. Itoh, Appl Phys B-Lasers O, 87 (2007) 85-89.

[15] F. Ribeiro, J. Macaira, R. Cruz, J. Gabriel, L. Andrade, A. Mendes, Sol Energ Mat Sol C, 96 (2012) 43-49.

[16] R. Cruz, J.A. da Cruz Ranita, J. Maçaira, F. Ribeiro, A.M.B. da Silva, J.M. Oliveira, M.H.F. Fernandes, H.A. Ribeiro, J.G. Mendes, A. Mendes, (2012).

[17] P.J. Holliman, M.L. Davies, A. Connell, B.V. Velasco, T.M. Watson, Chem Commun, 46 (2010) 7256-7258.

[18] J. Macaira, F. Ribeiro, L. Andrade, J. Gabriel, A. Mendes, in: CHEMPOR 2011 : 11th International Chemical and Biological Engineering Conference, Lisbon, Portugal, 2011, pp. 299-300.

[19] S.Y. Dai, J. Weng, Y.F. Sui, S.H. Chen, S.F. Xiao, Y. Huang, F.T. Kong, X. Pan, L.H. Hu, C.N. Zhang, K.J. Wang, Inorg Chim Acta, 361 (2008) 786-791.

[20] L.T. Han, A. Fukui, Y. Chiba, A. Islam, R. Komiya, N. Fuke, N. Koide, R. Yamanaka, M. Shimizu, Appl Phys Lett, 94 (2009) -.

[21] R. Sastrawan, Disertasi University of Freiburg, (2006).

[22] W.J. Lee, E. Ramasamy, D.Y. Lee, J.S. Song, J Photoch Photobio A, 183 (2006) 133-137. 
LEPABE - Laboratory for Process Engineering, Environment, Biotechnology and Energy

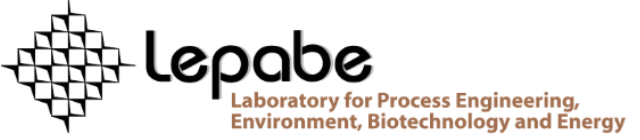

\section{U.PORTO}

FEUP FACULDADE DE ENGENHARIA DEPARTAMENTO DE UNIVERSIDADE DO PORTO $\mid$ ENGENHARIA QUÍMICA 